\title{
Prioritize the Development of Agriculture and Rural Areas, and Comprehensively Promote Rural Revitalization
}

\author{
Zihan Li \\ School of Economics and Management, Zhejiang Ocean University, Zhoushan 316022, Zhejiang, China
}

\begin{abstract}
Without agricultural and rural modernization, there would be no national modernization, and without rural revitalization, there would be no great rejuvenation of the Chinese nation. The Fifth Plenary Session of the 19th Central Committee of the Communist Party of China proposed that the goal of "giving priority to the development of agriculture and rural areas and comprehensively promoting rural revitalization" is to increase efforts to continue the work of "agriculture, rural areas and farmers" and to continue the comprehensive promotion of rural revitalization to make agricultural modernization, comprehensive rural progress, and comprehensive rural development. develop. Consolidating the basics Agriculture is the cornerstone of people's stability and the key to national governance with a population of 1.4 billion. Agriculture must be developed. No matter where industrialization and urbanization are advanced, villages must not perish, and cities and rural areas must coexist. As General Secretary Xi Jinping pointed out, if in the process of modernization, "the city is prosperous on one side and the countryside is on the other side", "this kind of modernization cannot be successful". To comprehensively build a new path for a modern socialist country, we must follow the objective laws of economic development, make the resolution of "agriculture, rural areas, and farmers" the top priority of the party's work, insist on giving priority to development, and comprehensively promote rural revitalization. The general trend of taking the realization of socialist modernization as the long-term goal.
\end{abstract}

Keywords: Rural revitalization, Urban-rural integration, Featured Industry.

\section{Introduction}

\subsection{Research Background}

The "three rural issues" is an important issue that my country has always paid attention to. Through a series of measures such as the construction of a new socialist countryside, agricultural modernization, and structural reforms in agricultural supply, as the income of farmers in my country continues to increase, the outlook of agriculture and rural areas is greatly improved. The improvement has laid a good foundation for the implementation of the rural revitalization strategy. However, the problem of unbalanced development in my country is still the most obvious in rural areas. For example, for the income of urban and rural residents, the income ratio of urban and rural residents in my country was $2.8 \%$ in 2012 , and the ratio in 2016 was $2.72 \%$, there is no effective reduction, in order to achieve the two hundred-year development goals, rural revitalization, industry first. In 2018, the Central Government of the Communist Party of China announced the "Several Opinions of the State Council on the Implementation of the Rural Revitalization Strategy." Only by revitalizing rural industries can we revitalize talent, capital and other factors. Concentrate on rural areas, promote farmers' income growth, and form a virtuous circle of rural development. The characteristics of rural development must be respected. In 2019, the development of rural industries depends on local agriculture and rural resources. It is clear that the region needs to develop characteristics and characteristics. Characteristic industries. The development of characteristic industries is an effective way to promote the integration of 1,2, and 3 industries. It is a correct strategy for poverty relief. It is the main reason for the formation of a "one town, one product", "one town, one product" or "featured town" area across the country. It is a practical measure to promote the prosperity of rural industries and promote rural revitalization by exploring the development of rural characteristic industries. In the context of implementing the rural revitalization strategy, it is necessary to strengthen the optimization research on the development of rural characteristic industries.

\subsection{Research Content}

In order to accelerate the development of the rural economy in an all-round way, it is beneficial to change the overall development of my country's rural economy. In this process, with the goal of promoting urban-rural integration and rural revitalization, we will promote agricultural modernization in accordance with the development strategy put forward by the 19th National Congress of the Communist Party of China. Integrate urban resources, reform and improve rural economic development methods. Taking urban development to drive rural development as the basic policy and strategy, reform the traditional rural economic development method, reflect the new situation of modern development, and explore new development in the process of industrial development and human development in rural areas in different regions. In connection with the development goals of the new era, the promotion of urban-rural integration must be taken as the development goal. In the process of continuous exploration, it is necessary to explore a road of revitalization suitable for the development of rural areas in our country. This path is our goal of achieving small wealth in a practical and comprehensive way. 


\subsection{Research Methods}

This article mainly adopts the method of literature research. The literature mainly focuses on rural revitalization strategy, urban-rural integration, rural characteristic industries, rural reforms, agricultural industrialization, agricultural specialization, regional economic development, regional industries, characteristic industries, and animal husbandry regional complexes, etc. Fields, focusing on the above-mentioned relevant policy documents, books, reading and research publications, doctoral dissertations, electronic literature, and local unit data, etc., analyze and organize the analysis results, and integrate the analysis results into the writing.

\section{Difficulty Analysis}

\subsection{Unbalanced Urban and Rural Development}

The unbalanced development of my country's urban and rural areas is facing more complex problems. China is a multi-ethnic country with a large population and diverse geographical environment. In the course of more than 5,000 years of historical development, the respective characteristics of urban and rural areas have gradually emerged in the process of development. After being greatly influenced by the reform and opening policy, some cities in our country have realized the development of urbanization. Due to the unequal economic support between urban and rural areas in their respective development processes, the economic development of urban and rural areas is even more unequal and the importance of cultural education is different. As time goes by, the disadvantages of urban and rural development gradually appear, and urban and rural development The imbalance in the country continues to expand. Due to differences in national support and resources, rural development will lag behind urban development.

\subsection{Difficulties in the Development of Characteristic Industries in the Process of Urban-rural Integration}

General Secretary Xi Jinping emphasized: Promote the revitalization of rural industries, focus on the development of modern agriculture, and focus on promoting the integrated development of rural primary, secondary and tertiary industries. Establish a rural industrial system and achieve industrial prosperity. The characteristic rural industry is an important part of the rural industry. Although the development of characteristic industries has achieved certain results in the process of urban-rural integration in recent years, the development of characteristic industries in rural areas is a dynamic and long-term process. Affected by many factors such as the role of the government, human resources, capital investment, etc., it is not easy to establish a complex collaborative development system. Through the analysis of relevant texts and the main subjects of the government, enterprises, and farmers participating in the development of rural characteristic industries in the process of urban-rural integration.
If there is only agriculture in the countryside, then economic development will be very difficult. In the third stage, the only way to promote the development of rural industrialization is to integrate the rural industrial structure with the rural industrial structure. It has long been in the leading position of the "green building evaluation standard", but relatively speaking, the second and third sources of income can bring more income. Industry development is insufficient. Data shows that the output value of the agricultural service industry only accounts for $1 \%$ of the output value of the primary industry, which is not conducive to the integration of the primary, secondary, and tertiary industries. At the same time, the degree of technological integration is relatively low in the development of characteristic rural industries. Industrial integration means that the social service industry must effectively realize scientific and technological innovation and industrial innovation from all aspects related to production in the production process, in the production of agricultural materials and technology, and in the process of industrial integration, technological innovation and industrial innovation. Technical achievements. In order to respond to market changes, a market operation control system based on information technology and big data technology should be established to carry out market forecasts and market forecasts, and realize preparations for early warning. On the one hand, the application of rural technology in the production process is relatively backward. The technology that has developed in step with the times has not yet penetrated into the entire process of production, processing, and transportation. In the case of a low degree of technological integration, the application of technology in the production process of characteristic industries is relatively low. This stagnation further increases the barriers to integration.

\subsection{The Degree of Perfection of the System}

In the new era, due to the integration of urban and rural areas, the system for promoting rural revitalization is imperfect. In the process of promoting rural revitalization, there is no clear direction. In the development process of many towns and villages, there is basically a phenomenon of "crossing the river by touching stones". Conducive to rural development. First, due to the imperfect policy system for urban integration to promote rural revitalization, it is impossible to ensure the interconnection between urban resources and rural resources. There is a lack of linkage between villages in the development process. Second, there is no standardization in the development process. The system of capital investment and use is unbalanced and cannot fully support the rural areas. Third, due to the imperfect system, rural land resources cannot be used rationally. There are contradictions between rural land use and the political system, the land utilization rate is low, and rural people's ideological and political awareness Low, low coordination. The social security system for the rural population is not sound, the deployment policy is not clear, and the minimum security policy must be improved.

Fourth, local policies are imperfect, and decision-making is fragmented and unanimous. The township government strictly subdivides higher-level instructions according to "document 
politics", making policy support lagging behind the project development schedule. Horizontal and vertical government agencies often do this. Due to poor cooperation, policies are affected by the information island effect, and they are introduced independently, which aggravates the difficulties of enterprises and farmers for capital competition. On the other hand, local government actions have caused the development of rural characteristic industries. The impact is mainly reflected in the government and system distribution. The healthy development of industries cannot be without order and regulation. There are policy loopholes in the development of rural characteristic industries, and they often only focus on early support and support. The lack of supervision and maintenance of system construction in the later period is obvious.

\subsection{Brain Drain}

Talent revitalization means industry revitalization. In the rural revitalization strategy system, talent revitalization is an important part of the development of characteristic agriculture. In the process of industrial integration, not only professional talents in specific fields are needed, but also compound talents are needed for the culture, technology, operation and comprehensive services of the rural frontline. In the process of rural development, due to insufficient talent training, it is hoped that the majority of urban talents will work at the grassroots level due to poor rural conditions during the work process. In the process of achieving the goal of rural revitalization, if human resources have been in a state of excessive shortage, it will definitely not Conducive to overall development, it will inevitably have an impact on the development of the village. However, in terms of talent training in rural areas, the current education model is relatively backward, and the level of education is relatively backward. In the process of revitalizing rural development, the level of cooperation is low, and the ability to understand national policies is limited, which is prone to a sense of conflict.

The impact of human resources on the development of rural characteristic industries is mainly reflected in the total number of talents and the structural ratio. On the one hand, the amount of labor is on the one hand. In the early stage of reform and opening up, because of the population distribution of manufacturing enterprises in my country, in order to save labor costs, these coastal enterprises brought rapid economic development to the eastern region. Population distribution is also an important condition for China to quickly become a "world factory". Sufficient labor not only reduces the support of the population, but also brings more surplus capital to the development of rural characteristic industries. At present, the same problem exists in modern rural areas. If the recruitment system is not perfect, it will be difficult to fundamentally change the status quo of rural talent recruitment. We must use talents to create a good competitive environment and deepen the reform of the talent system.

\section{Specific Countermeasures}

\subsection{Basic Principles of Rural Revitalization}

The development of rural characteristic industries under the rural revitalization strategy must adhere to the five basic principles of party leadership, adapting measures to local conditions, combining construction and management, and multi-subject participation.

First, leading by party building, planning first. Persist in the party's leadership in rural work and guide the development of rural industries, give full play to the leadership role of the party organization at the grassroots level in rural areas, unite and lead the party members to work together to build a beautiful hometown, and guide the villagers to build a co-governance and share. On the basis of the implementation of "multiple regulations in one" in modern rural areas, improve and revise the layout plan of market towns and villages and the development plan of village construction to provide planning basis for the scientific and reasonable development of rural characteristic industries.

Second, adjust measures to local conditions and advance by classification. According to the local characteristics of natural and human resources, the level of social and economic development, and geographical location conditions, the layout should be targeted. Governments at all levels should do a good job of top-level design and classified policies for the development of domestic rural characteristic industries. It not only pays attention to difference and individualization, but also pays attention to unified name organization and overall planning.

Third, focus on long-term effectiveness, and pay equal attention to construction and management. All regions and departments should strengthen communication and coordination, and pay equal attention to the establishment and supervision and maintenance of the rural characteristic industry system, including improving the policy support system and a stable and long-term working mechanism. Ensure the long-term growth and prosperity of rural characteristic industries.

Fourth, government guidance and social participation. Confirm the government's leading position in the development of rural characteristic industries, and mobilize all forces to support the priority development of rural characteristic industries. Strive for policy support, mobilize local talents, encourage industrial and commercial capital to go to the countryside, let more resources, projects, and funds participate in the creation of hometown memories, and accelerate the process of promoting the overall prosperity of rural industries with rural characteristic industries.

Fifth, led by demonstration and demonstration. Through investigation and research, select 1-2 administrative villages 
with a good industrial foundation, rich cultural heritage, and development motivation of the village-level leadership team as the first demonstration villages for characteristic industries, and give priority to development, accumulate experience, and create a template for the implementation of the rural revitalization strategy across the country, Set a benchmark.

\subsection{Enhance the Mutual Dynamics between Urban and Rural Areas}

In the development process, we must first open up urban-rural connections and improve urban-rural interaction capabilities. As part of building a well-off society in an all-round way, it is necessary to clarify the role of villages, counties, and cities in the development process and fully understand the importance of rural revitalization. In order to promote the common development between urban and rural areas, it is necessary to realize that urban development is the basis for rural revitalization. In the process of urban development, it is necessary to realize the close connection between the city and the countryside. Through continuous communication and integration, the interaction between towns and villages is obviously strengthened. In the development process, it is necessary to clarify the pillars of the rural revitalization development strategy, fill the gaps in the rural development process, and combine the dividends of urban development to promote rural revitalization and rural development.

\subsection{Optimize talent construction}

To improve the efficiency of urban-rural integration, it is necessary to build a high-quality and high-level talent team, optimize the overall strength of the talent team, and provide various types of outstanding talents for rural development. Combining rural characteristics and pertinence, strengthen talent education. Improve the rural talent policy to attract high-quality talents and improve the overall strength of rural cadres. Through regular refresher training, learn the latest knowledge in time, take "three meetings and one lesson" as the central goal of training, comprehensively improve the ideological understanding of rural managers, and continuously send outstanding talents to rural areas, and make contributions to rural construction and development.

Improve the talent introduction mechanism. Highlight the development direction of emerging industries in rural areas, pay close attention to the unique resources of different regions, coordinate and adapt various talent teams to meet the talent needs in the innovation and development of rural industries, and promote the optimization and upgrading of the industrial structure. The key method is to improve the flexible talent flow mechanism, clarify the goal based on the combination of modern rural urban economic development and comprehensive competitiveness, and in line with the tenet of "not asking for everything, but seeking what is used", through encouraging talents and technology to invest in shares and high-paying hiring, etc. Ways to attract talents from all walks of life to devote themselves to the construction of rural characteristic industries.
Have a comprehensive understanding of the local talent situation. It is necessary to establish and improve the local talent pool. Through the combination of traditional community visits and modern information platforms, more local talents, including those who work hard outside, should be absorbed into the "talent pool", and the talent resources should be fully organized to enhance the internal talent pool of the region. Communication and mutual assistance. Only on the basis of fully understanding the distribution and structure of local human resources, can the targeted introduction of human resources policies that conform to local characteristics.

\section{Conclusion}

In short, based on the theoretical basis of urban-rural integration and development of characteristic industries and rural revitalization, rural revitalization is a prerequisite for the development of national modernization. The construction of new urbanization must be based on the revitalization of the countryside. Without the revitalization and integration of rural functions, urbanization cannot be realized. Effectively implement urban-rural integration to promote rural revitalization and development; in the development process, combine urban-rural linkages, improve urban-rural interaction, ensure that there is an effective institutional guarantee for urban-rural integration, implement urban and rural construction, integrate urban and rural resources, and realize benefits Complement each other, optimize the talent team, and effectively realize the integration of urban and rural development.

Rejuvenate the countryside and achieve the goal of building a well-off society in an all-round way. The topic of "agriculture, rural areas, and farmers" has always been something that all countries have been doing. China is a big agricultural country. The "three rural" issues are related to the economy and people's livelihood. The question is whether the overall efforts of my country's modernization can proceed smoothly. The proposal and implementation of the rural revitalization strategy is an important measure and necessary means to solve the "three rural" issues at this stage. With the continuous implementation and improvement of the rural revitalization strategy, the prosperity of rural industries has driven the prosperity of various industries. The pace of developing rural characteristic industries in the integration of urban and rural areas cannot be delayed.

\section{References}

[1] Fei Xiaotong. Rural China[M]. Shanghai: East China Normal University Press, 2018.

[2] Hayami Yujiro et al. Agricultural Development: International Prospects[M]. Wu Weidong, Trans. Beijing: The Commercial Press. 2014.

[3] Wu Xinmu et al. Introduction to County Economy[M]. Beijing: CPC Central Party School Press, 1988.

[4] $\mathrm{Wu}$ Dianqing. Regional Analysis and Planning Course[M]. Beijing: Beijing Normal University Press, 2008. 
[5] Hunan Provincial People's Government Development Research Center. Hunan County Economic and Social Development Report in 2014[M]. Beijing: Social Science Literature Publishing House, 2014.

[6] Wang Fayuan, et al. Research on the development of characteristic agriculture under the background of rural revitalization strategy[M]. Beijing: China Agriculture Press, 2018.

[7] Zhang Dengguo. Grassroots Governance and Rural Revitalization: The Action Paradigm of the First Secretary of Youth[J]. Chinese Youth Studies, 2019(09): 25-30.

[8] Yu Jianrong. The revitalization of rural industries must adapt to local conditions[J]. People's Forum, 2018(17): 64-65.

[9] $\mathrm{Yu}$ Xinrong. The key to poverty alleviation with characteristic industries is "precision" [J]. Administrative Management Reform, 2016, (04): 25-28.

[10] Hu Jiliang, Chen Yao. A Probe into the Cultivation of Characteristic Industries for Targeted Poverty Alleviation-A Case Study of Zhuxi County in Qinba Mountains[J]. Journal of South-Central University for Nationalities (Humanities and Social Sciences Edition), 2018, 38(04): 166-170.

[11] Hu Yuwei. Research on the development and optimization of Linxiang's rural characteristic industries under the strategy of rural revitalization[D]. Hunan Normal University, 2011.

[12] Li Huijuan. Research on the construction of a socialist urban-rural integration development system with Chinese characteristics in the new era [D]. Hohhot: Inner Mongolia Normal University, 2020.

[13] Xuan Jing. Research on rural revitalization strategy from the perspective of Marxist urban-rural relationship theory[D]. Lanzhou: Northwest University for Nationalities, 2020.

[14] Zhang Yanman. Research on the Urban-rural Integration Development System with Chinese Characteristics in the New Era[D]Changchun: Jilin University, 2020.

[15] Williams D S. Place-based approaches to rural economic revitalization: A public funding analysis and implications for the Alabama Black Belt[J]. 2010, 8.

\section{Author Profile}

Zihan Li (1997-), Postgraduate of the School of Economics and Management, Zhejiang Ocean University. Born in Dongying City, Shandong Province, his professional name is Agricultural Management. 